OPEN ACCESS

Edited by:

Yiqiu Tan,

Harbin Institute of Technology, China

Reviewed by:

Yuqing Zhang,

Aston University, United Kingdom Andreas Loizos,

National Technical University of Athens, Greece

*Correspondence: Jin Yang yj929@163.com Tingyi Xu

xutingyi@tongji.edu.cn

Specialty section:

This article was submitted to Structural Materials,

a section of the journal

Frontiers in Materials

Received: 29 February 2020

Accepted: 08 June 2020

Published: 06 August 2020

Citation:

Chen Z, Liang Y, Yang J, Xu T and Sun L (2020) Improved Design Method of Emulsified Asphalt Cold Recycled Mixture.

Front. Mater. 7:207.

doi: 10.3389/fmats.2020.00207

\section{Improved Design Method of Emulsified Asphalt Cold Recycled Mixture}

\author{
Zhang Chen ${ }^{1}$, Yuanlu Liang ${ }^{1}$, Jin Yang ${ }^{2 *}$, Tingyi $X_{u^{1 *}}$ and Lijun Sun ${ }^{1}$ \\ ${ }^{1}$ The Key Laboratory of Road and Traffic Engineering, Ministry of Education, Tongji University, Shanghai, China, ${ }^{2}$ Shenzhen \\ High Speed Engineering Consulting Co., Ltd., Shenzhen, China
}

This paper proposes an improved design method for emulsified asphalt cold recycled mixture (EACRM) so as to solve the "secondary compaction" problem in cold recycled asphalt pavement. First, a temperature prediction equation is established based on measured data of cold recycled asphalt pavement. The equation provides the basis for improving the design method. Second, regarding the shortcomings of the current design methods, we introduce material design principles of EACRM and improve existing methods. Splitting strength $\left(15^{\circ} \mathrm{C}\right)$ and unconfined compressive strength $\left(60^{\circ} \mathrm{C}\right)$ are chosen as the basis of a double index to determine the asphalt emulsion content. Finally, the performance of the asphalt mixture created using the improved design method is compared to that using the current specifications of China. The results of the comparison validate that the proposed design method can effectively avoid early damage to cold recycled asphalt pavement.

Keywords: road engineering, design method, cold recycled mixture, asphalt emulsion, secondary compaction

\section{INTRODUCTION}

Cold recycled mixture is a technique for recycling reclaimed asphalt pavement (RAP) using emulsified bituminous binder, foamed asphalt binder, cement, fly ash, or lime powder as the additives without the application of heat (Mohammad et al., 2003; Kuna et al., 2017). Among cold recycling technologies, the use of emulsified asphalt binder for cold regeneration has rapidly become popular (Wang et al., 2009; Liu, 2011).

Most current design methods for emulsified asphalt cold recycled mixture (EACRM) are empirical or regional, and an international standard has not yet been implemented (Tan et al., 2005). Generally, the design methods of EACRM are mostly modified design methods of hot mix asphalt (HMA; Deng and Huang, 2001; Lu, 2001). Amendments to the Marshall Act, the amendment of the Verme method, the Oregon estimation design method, and the Swedish Akzo Nobel design method were proposed by the American Asphalt Regeneration Association (Asphalt Recycling and Reclaiming Association [ARRA], 1996, 2001) and the South African Asphalt Association proposed the "three levels" (level-traffic) design method (Zhang et al., 2015; Li et al., 2016). The Chinese design specification of EACRM was modified on the basis of the Marshall test method (Research Institute of Highway Ministry of Transport [RIOH], 2008).

The technical performance of EACRM designed with different RAP contents, cement contents, and gradation has been evaluated according to high-temperature stability (rutting test), lowtemperature crack resistance (low-temperature bending test), and water stability (freeze-thaw split test and immersion Marshall test) (Wu et al., 2009; Sravani et al., 2015). Creep and fatigue tests 
were used to evaluate the fatigue characteristics of EACRM by controlling the stress or strain levels, and corresponding fatigue failure characteristics and general rules were obtained (Pouliot et al., 2003; Jiang and Han, 2018). All the above studies used the heavy indoor compaction and Marshall methods to prepare specimens, but these molding methods cannot effectively simulate actual construction in the field (Li et al., 2019).

The cold recycled mixture is mainly utilized in the base course of the pavement (Modarres and Ayar, 2014). Hot mix asphalt should be paved on the cold recycled mixture to meet the requirements of road use. In the construction process of HMA, the cold recycled mixture is heated and further compacted with the effect of paving, which is called the "secondary compaction" process of the cold recycled mixture. However, this compaction process is not considered in the existing design method. Most studies only considered the state after the construction of the cold recycled mixture, resulting in a large deviation in the design results of the mixture ratio of the cold recycled mixture. This deviation can lead to serious early pavement damage. In view of this, this paper considers the influence of different construction seasons and the secondary compaction process. Based on the existing design method of cold recycled mixture, the indoor test method of EACRM is improved, and a design method of EACRM considering different construction seasons and the secondary compaction process is proposed. The research results are of referential value in engineering practice.

\section{SECONDARY COMPACTION IN COLD RECYCLED ASPHALT PAVEMENT}

\section{Finding of Secondary Compaction}

In the technological transformation project of the NanchangJiujiang Expressway in Jiangxi Province, China, the technical scheme of EACRM used in the upper base of the pavement was implemented. Pavement structure from top to bottom was: $4 \mathrm{~cm}$ HMA upper layer, $6 \mathrm{~cm}$ HMA middle layer, $6 \mathrm{~cm}$ lower layer, $12 \mathrm{~cm}$ cold recycled mixture upper base, $22 \mathrm{~cm}$ water stable macadam base, $33 \mathrm{~cm}$ subbase, and original subgrade. Reclaimed asphalt pavement was divided into two grades: $0-10 \mathrm{~mm}$ (fine) and $10-31.5 \mathrm{~mm}$ (coarse). The proportion of RAP and mineral powder used in the project was coarse rap: fine rap: mineral powder $=43: 57: 2.4$. The actual gradation results are shown in Table 1.

The construction went well in winter. In addition, after opening to traffic, the performance of the pavement was good. However, in the summer of the second year, with the same design and construction, deep ruts occurred after opening to traffic, as shown in Figure 1. So, the temperature rise is the most important factor leading to deep ruts.

TABLE 1 | Passing rate of the key sieve for the design mixture.

\begin{tabular}{lccccccc}
\hline Sieve size/mm & 26.5 & 19 & 9.5 & 4.75 & 2.36 & 0.3 & 0.075 \\
Passing rate/\% & 100 & 99.4 & 67.0 & 44.3 & 29.2 & 9.1 & 4.9
\end{tabular}

In order to determine the cause of rutting, the construction technicians excavated the pavement where the ruts occurred, as shown in Figure 2. At the rut, the thickness of the HMA hardly decreased, while the cold recycled layer was obviously squeezed, which indicates that the deep ruts were formed because the EACRM, not the HMA, was further compacted. We refer to this process of further compaction of the EACRM after HMA paving as "secondary compaction."

In order to confirm secondary compaction, the technicians directly chiseled with a piece of machinery similar to a road cutting machine, and then excavated the pavement manually. Finally, core drilling samples were taken in the cold recycled asphalt pavement before and after paving the HMA. Comparing the voidage of samples, it can be seen from Table 2 that the

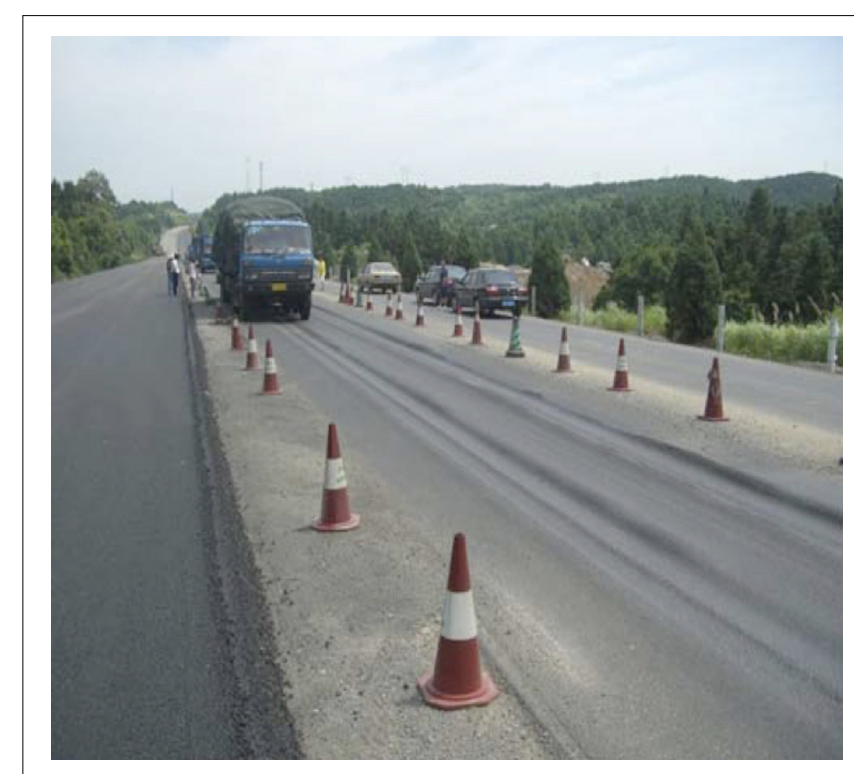

FIGURE 1 | Deep ruts.

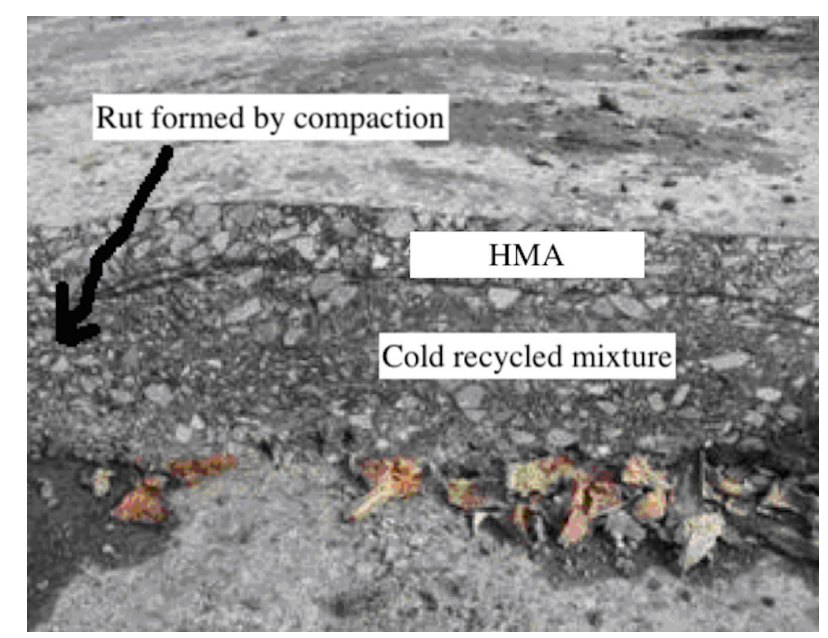

FIGURE 2 | Cross section of the rut. 
voidage of EACRM decreased significantly after HMA paving, which had a great impact on the performance of the EACRM.

\section{Analysis of Secondary Compaction}

The compaction of EACRM can be divided into two processes. The first compaction process occurs when the EACRM is rolled after it is paved at a normal temperature. In this process, the EACRM is compacted at a normal temperature. After this first compaction process, the voidage of mixture is generally about $11-14 \%$, as seen in Table 2 . This voidage is much higher than the technical requirement of HMA, which is about $4 \%$. Thus, emulsified asphalt cold recycled can be further compacted.

The secondary compaction occurs in the HMA paving process. When paving HMA, the heat will be transferred downward, which will cause the temperature of the EACRM to rise. In addition, with repeated rolling, the cold recycled layer with large voidage will be further compacted.

This secondary compaction leads to a decrease of the voidage of the EACRM, which leads to significant changes in the performance of the EACRM. Existing design methods have not taken this process into account, resulting in a large difference between the design results and the actual situation, and the cold recycled asphalt pavement structure may suffer early damage.

\section{Temperature Measurement and Prediction Equation in Secondary Compaction}

As discussed in sections "Finding of Secondary Compaction" and "Analysis of Secondary Compaction," the temperature rise is the most important factor leading to secondary compaction. In order to provide a basis for improving the existing design methods of cold recycled mixture, the temperature in the cold recycled layer was measured and analyzed.

\section{Temperature Measurement}

The temperature transducers with a wire, a display, and a sensor utilized in the experiment were common and easy to use. One end of the wire is a sensor, and the other end is a temperature display. Before paving the cold recycled layer, the sensors were placed at different depths $(2,4,6,8,10$, and $12 \mathrm{~cm})$. When

TABLE 2 | Voidage before and after paving HMA (\%).

\begin{tabular}{lcc}
\hline Voidage before paving HMA & Voidage after paving HMA & Reduction \\
\hline 11.9 & 9.5 & 2.4 \\
13.3 & 9.6 & 3.7 \\
12.7 & 9.4 & 3.3 \\
13.7 & 10.9 & 2.8 \\
12.5 & 9.4 & 3.1 \\
13.2 & 10.5 & 2.7 \\
12 & 8.8 & 3.2 \\
11.4 & 9.1 & 2.3 \\
12.3 & 8.9 & 3.4 \\
12.6 (average) & 9.6 (average) & 3.0 (average)
\end{tabular}

paving the cold recycled layer, no data were recorded, and the sensors were left in the new cold recycled layer. The timeline began when HMA was paved above the temperature sensors and the air temperature and initial temperature at each depth of the cold recycled asphalt pavement were recorded at the zero point. Then, the temperature data at different depths were recorded every $5 \mathrm{~min}$. The time from paving to the rolling of HMA was generally about $1 \mathrm{~h}$, and the recording time of the temperature data in the cold recycled asphalt pavement was extended by $1 \mathrm{~h}$, for a total time of $2 \mathrm{~h}$. Three groups of temperature data are shown in Tables 3-5.

\section{Temperature Prediction Equation}

The value of the temperature difference, $\Delta T$, is the value by which the temperature at a certain depth of cold recycled asphalt pavement was more than the initial temperature value. Figure 3 presents that the $\Delta T$ curves of different measured data points at the same depth are very similar. Thus, in the temperature prediction equation of the cold recycled asphalt pavement, $\Delta T$ is determined as the dependent variable, while time $t$ and depth $H$ are determined as independent variables.

In this study, it was found that $\Delta \mathrm{T}$ has a good correlation with the third power of time $t$ and the square of depth $H$. Therefore,

TABLE 3 | The first group of temperature data; air temperature $21^{\circ} \mathrm{C}$, HMA temperature $160^{\circ} \mathrm{C}$.

\begin{tabular}{|c|c|c|c|}
\hline \multirow[b]{3}{*}{ Time (min) } & \multicolumn{3}{|c|}{ Temperature $\left({ }^{\circ} \mathrm{C}\right)$} \\
\hline & \multicolumn{3}{|c|}{ Depth } \\
\hline & $4 \mathrm{~cm}$ & $8 \mathrm{~cm}$ & $12 \mathrm{~cm}$ \\
\hline 0 & 22.3 & 21.5 & 21.1 \\
\hline 5 & 24.8 & 21.6 & 21.1 \\
\hline 10 & 30.7 & 21.8 & 21.1 \\
\hline 15 & 35.5 & 22.2 & 21.1 \\
\hline 20 & 40.7 & 22.8 & 21.3 \\
\hline 25 & 44.7 & 23.8 & 21.7 \\
\hline 30 & 47.9 & 25.1 & 22.2 \\
\hline 35 & 51 & 26.3 & 23.1 \\
\hline 40 & 53.3 & 27.6 & 24 \\
\hline 45 & 55.1 & 29.2 & 24.8 \\
\hline 50 & 56.3 & 30.8 & 25.6 \\
\hline 55 & 57.3 & 31.8 & 26.4 \\
\hline 60 & 58.3 & 32.7 & 27.3 \\
\hline 65 & 58.9 & 33.7 & 28.3 \\
\hline 70 & 59.7 & 34.8 & 29.4 \\
\hline 75 & 60.3 & 35.6 & 30.6 \\
\hline 80 & 60.2 & 36.4 & 31.4 \\
\hline 85 & 60 & 37 & 32 \\
\hline 90 & 59.6 & 37.5 & 32.4 \\
\hline 95 & 59 & 38 & 32.6 \\
\hline 100 & 58.3 & 38.5 & 32.8 \\
\hline 105 & 57.6 & 38.9 & 33 \\
\hline 110 & 56.9 & 39.3 & 33.2 \\
\hline 115 & 56.1 & 39.7 & 33.4 \\
\hline 120 & 55.2 & 40.1 & 33.7 \\
\hline
\end{tabular}


TABLE 4 | The second group of temperature data; air temperature $20^{\circ} \mathrm{C}, \mathrm{HMA}$ temperature $155^{\circ} \mathrm{C}$.

\begin{tabular}{|c|c|c|c|c|}
\hline \multirow[b]{3}{*}{ Time (min) } & \multicolumn{4}{|c|}{ Temperature $\left({ }^{\circ} \mathrm{C}\right)$} \\
\hline & \multicolumn{4}{|c|}{ Depth } \\
\hline & $2 \mathrm{~cm}$ & $4 \mathrm{~cm}$ & $6 \mathrm{~cm}$ & $12 \mathrm{~cm}$ \\
\hline 0 & 21 & 20.8 & 16.9 & 16.1 \\
\hline 5 & 27.2 & 22.9 & 16.9 & 16.1 \\
\hline 10 & 47.3 & 28.4 & 17 & 16.1 \\
\hline 15 & 58.6 & 33.2 & 17.7 & 16.1 \\
\hline 20 & 61.9 & 38 & 18.6 & 16.3 \\
\hline 25 & 66.5 & 42 & 20.1 & 16.8 \\
\hline 30 & 68.8 & 45.6 & 21.9 & 17.3 \\
\hline 35 & 69.9 & 48.1 & 23.7 & 18.3 \\
\hline 40 & 70.1 & 50.4 & 25.4 & 19.2 \\
\hline 45 & 70.1 & 52 & 27.2 & 20 \\
\hline 50 & 69.9 & 53.6 & 28.8 & 20.8 \\
\hline 55 & 69.5 & 54.6 & 30.4 & 21.6 \\
\hline 60 & 69.1 & 55.2 & 31.9 & 22.5 \\
\hline 65 & 68.6 & 55.8 & 33.2 & 23.5 \\
\hline 70 & 67.9 & 55.8 & 34.4 & 24.8 \\
\hline 75 & 67.1 & 55.6 & 35.4 & 26 \\
\hline 80 & 66.3 & 55.3 & 36.2 & 26.8 \\
\hline 85 & 65.6 & 54.9 & 36.7 & 27.4 \\
\hline 90 & 64.9 & 54.5 & 37.2 & 27.8 \\
\hline 95 & 64.1 & 54.1 & 37.7 & 28 \\
\hline 100 & 63.1 & 53.4 & 38 & 28.2 \\
\hline 105 & 61.9 & 52.8 & 38.2 & 28.4 \\
\hline 110 & 60.7 & 52.1 & 38.3 & 28.6 \\
\hline 115 & 59.3 & 51.4 & 38.4 & 28.8 \\
\hline 120 & 57.6 & 50.6 & 38.5 & 29.1 \\
\hline
\end{tabular}

the temperature prediction equation of the cold recycled asphalt pavement when paving HMA is:

$$
\begin{gathered}
T=\Delta T+T_{0} \\
\Delta T=\left(a H^{2}+b H+c\right) \times t^{3}+\left(d H^{2}+e H+f\right) \times t^{2}+ \\
\left(g H^{2}+h H+i\right) \times t
\end{gathered}
$$

where $T_{0}$ refers to the initial temperature of the cold recycled asphalt pavement. In engineering applications, $T_{0}$ can be generally determined according to the following conditions: when the daytime temperature is below $25^{\circ} \mathrm{C}, T_{0}$ can be determined as $25^{\circ} \mathrm{C}$; when the daytime temperature is above $25^{\circ} \mathrm{C}, T_{0}$ can be determined as $35^{\circ} \mathrm{C}$ (Yang et al., 2010). It should be noted that the daytime temperature here refers to the temperature on the day when HMA is paved on the cold recycled asphalt pavement and the temperature data of more than $120 \mathrm{~min}$ should not be estimated by this equation. $H$ is the depth of the cold recycled asphalt pavement, $\mathrm{cm}$; $t$ is time, $\min ; a, b, c, d, e, f$, $g, h$, and $i$ are coefficients.

The regression results are $a=0.00343, b=-0.0609, c=0.2217$, $d=-0.0802, e=1.4546, f=-5.6486, g=0.4867, h=-9.1549$, and $i=39.8135$.

\begin{tabular}{|c|c|c|c|c|}
\hline \multirow[b]{3}{*}{ Time (min) } & \multicolumn{4}{|c|}{ Temperature $\left({ }^{\circ} \mathrm{C}\right)$} \\
\hline & \multicolumn{4}{|c|}{ Depth } \\
\hline & $2 \mathrm{~cm}$ & $6 \mathrm{~cm}$ & $8 \mathrm{~cm}$ & $10 \mathrm{~cm}$ \\
\hline 0 & 15 & 15.3 & 15.2 & 15.1 \\
\hline 5 & 22.5 & 15.3 & 15.3 & 15.2 \\
\hline 10 & 46.5 & 15.4 & 15.5 & 15.3 \\
\hline 15 & 53.6 & 16.1 & 16 & 15.5 \\
\hline 20 & 61.3 & 17.4 & 16.6 & 15.7 \\
\hline 25 & 64.1 & 18.9 & 17.6 & 16.2 \\
\hline 30 & 66.8 & 20.9 & 19 & 16.9 \\
\hline 35 & 68.5 & 22.9 & 20.1 & 17.6 \\
\hline 40 & 69.9 & 24.6 & 21.5 & 18.5 \\
\hline 45 & 70.5 & 26.6 & 23.1 & 19.7 \\
\hline 50 & 70.7 & 28.4 & 24.7 & 21.1 \\
\hline 55 & 70.5 & 30.2 & 25.7 & 21.9 \\
\hline 60 & 70.1 & 31.7 & 26.8 & 22.6 \\
\hline 65 & 69.4 & 33 & 27.8 & 23.6 \\
\hline 70 & 68.7 & 34.2 & 28.9 & 24.6 \\
\hline 75 & 67.9 & 35.6 & 29.7 & 25.3 \\
\hline 80 & 67.3 & 36.4 & 30.5 & 26.1 \\
\hline 85 & 66.6 & 36.9 & 31.2 & 26.8 \\
\hline 90 & 65.9 & 37.4 & 31.8 & 27.4 \\
\hline 95 & 64.9 & 37.9 & 32.4 & 28 \\
\hline 100 & 63.9 & 38.4 & 32.8 & 28.6 \\
\hline 105 & 62.7 & 38.6 & 33.1 & 29.2 \\
\hline 110 & 61.3 & 38.9 & 33.5 & 29.7 \\
\hline 115 & 59.7 & 39.2 & 34 & 30.3 \\
\hline 120 & 58 & 39.5 & 34.4 & 30.9 \\
\hline
\end{tabular}

TABLE 5 | The third group of temperature data; air temperature $12^{\circ} \mathrm{C}, \mathrm{HMA}$ temperature $155^{\circ} \mathrm{C}$.

As shown in Figure 4, the temperature curves of the prediction equation are close to those of the measured temperature data, which indicates that the prediction effect is good. Moreover, the prediction effect of the equation needs to be verified using more measured data, and the coefficients in the equation can thus be further modified.

\section{IMPROVED DESIGN METHOD OF EMULSIFIED ASPHALT COLD RECYCLED MIXTURE}

Based on the physical indexes, such as void ratio of the core drilling samples of the test road and the temperature prediction equation, an improved design method was proposed in this section. In section "Specimen Shaping Method," on the basis of the comprehensive consideration of the existing design methods of EACRM, an improved specimen shaping method was put forward. In section "Design Indexes and Standards," design indexes and standards were introduced for the control of secondary compaction. 

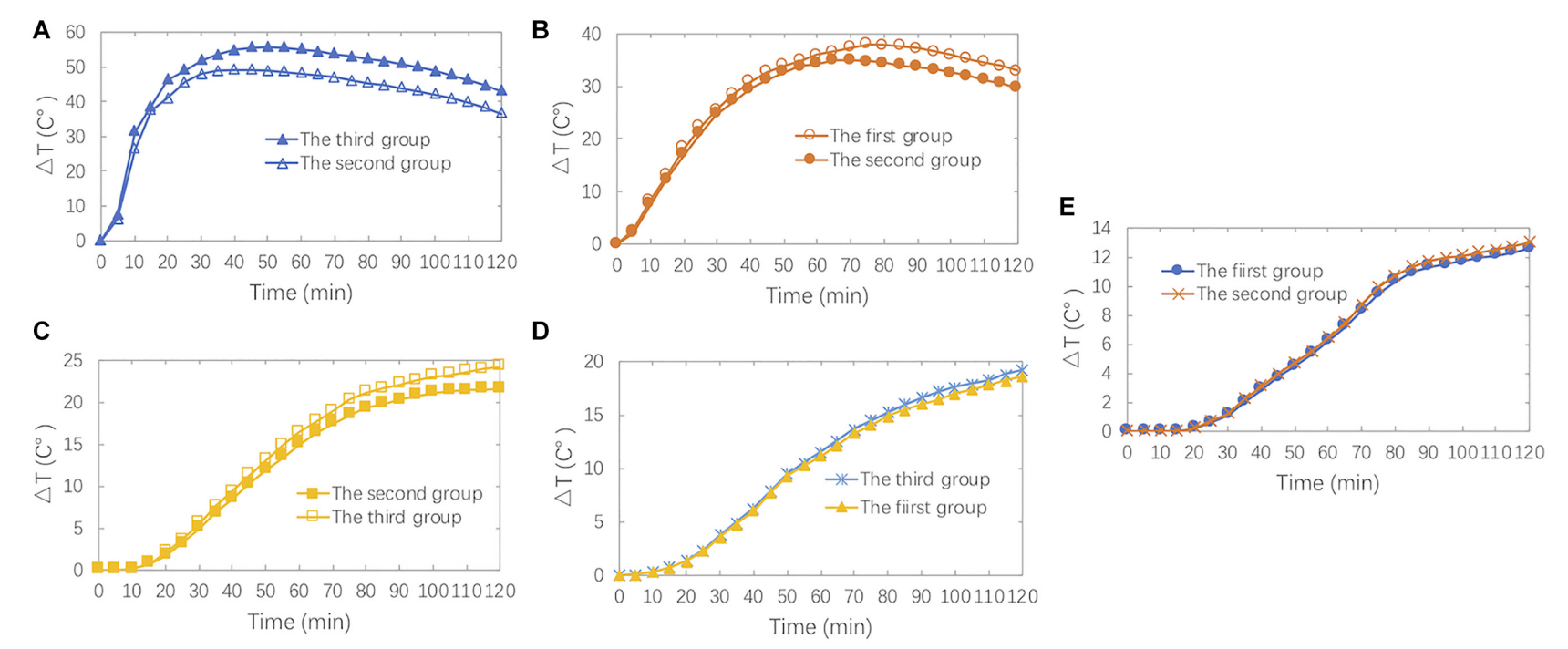

FIGURE 3 | $\Delta T$ curves at (A) $2 \mathrm{~cm}$, (B) $4 \mathrm{~cm}$, (C) $6 \mathrm{~cm}$, (D) $8 \mathrm{~cm}$, and (E) $12 \mathrm{~cm}$.

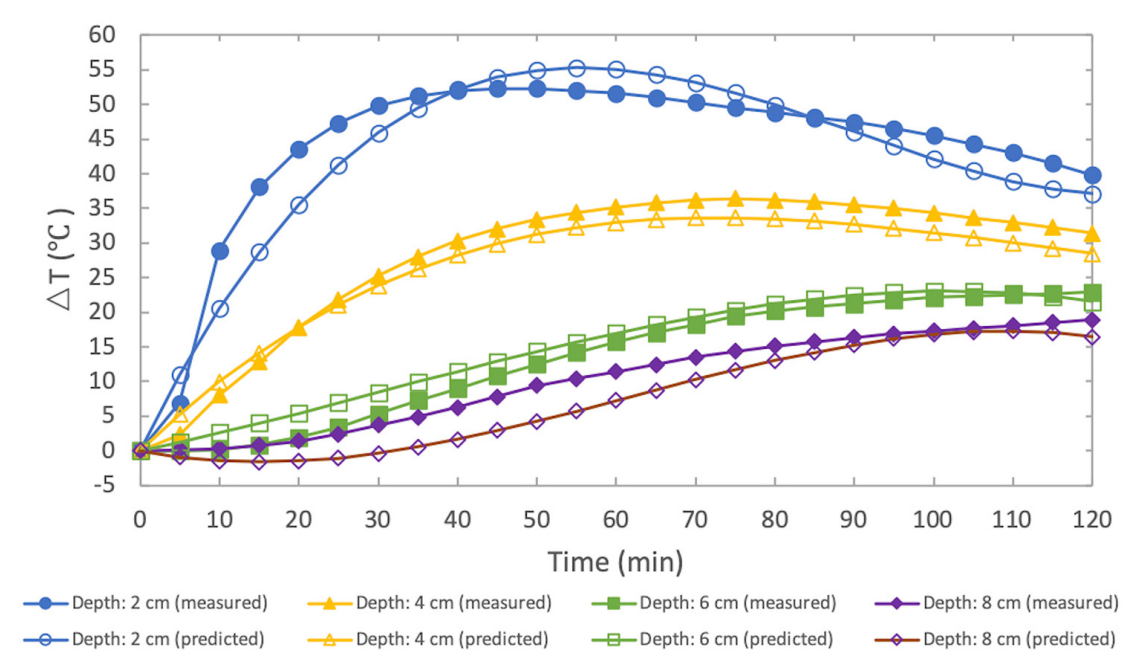

FIGURE 4 | Comparison between measured data and prediction data.

\section{Specimen Shaping Method}

A certain proportion of water needs to be added during the shaping process of the EACRM. However, there is no consensus method for the determination of the amount of water. It is generally believed that the higher the dry density, the greater the strength. Therefore, it is suitable that the water content (WC) corresponding to the maximum dry density is taken as the basis of the water addition.

In order to obtain the maximum dry density, the appropriate liquid content is needed for the cold recycled mixture. However, there is no universally accepted method to define and determine the most appropriate liquid content. After a large number of laboratory tests, it was found that the contribution of asphalt should not be equal to that of water, but nor can it be completely ignored. On this basis, the concept of "the optimal effective liquid content" (OLC) is proposed. The contributions of asphalt particles and water are 30 and $70 \%$, respectively, for the reason that the test results showed that the water ratio determined by the concept of the OLC was more in line with the coating requirements of the cold recycled mixture.

For example, in the geotechnical compaction test, the optimal water content (OWC) is $4.0 \%$, which is determined by the emulsified asphalt content whose asphalt-aggregate ratio is $4.0 \%$. Then, the OLC equation is:

$$
\begin{aligned}
\mathrm{OLC}= & (4.0 \%+4.0 \% \times 38.55 \%) \times 0.7+ \\
& 4.0 \% \times 60 \% \times 0.3=4.6 \%
\end{aligned}
$$

In the equation, 38.55 and $60 \%$, respectively, represent the proportions of water and asphalt in emulsified asphalt. If 
emulsified asphalt is added where the asphalt-aggregate ratio of is $5.0 \%$ when the specimen is shaped, the additional water content (WC) is:

$$
\begin{gathered}
\mathrm{WC}=(4.6 \%-5.0 \% \times 0.6 \times 0.3-5.0 \% \times 0.3855 \times 0.7) \\
\div 0.7=3.36 \%
\end{gathered}
$$

The key to simulating secondary compaction of the EACRM is to determine the number and temperature of each compaction. According to the current specifications in China, the number of the first compaction can be fixed as 50 times on both sides. Moreover, considering the temperature in different seasons, three different temperatures of 40,25 , and $10^{\circ} \mathrm{C}$ are adopted for the mixture mixing and compaction to correspond to the construction conditions in summer, spring, autumn, and winter, respectively.

Based on the temperature prediction equation in section "Temperature Prediction Equation," during construction in spring and autumn, the temperature of the second compaction can be set as $60^{\circ} \mathrm{C}$. As shown in Table 6, according to the $9.6 \%$ voidage value of core samples drilled in the field, it was determined that the number of the second compaction was about 46 times, which could be lowered to 45 times for convenience. In summer, the molding temperature of the second compaction can be determined as $70^{\circ} \mathrm{C}$ according to the temperature prediction equation.

In this paper, the specimen shaping method of EACRM is the modified Marshall compaction method, which is modified based on the above analysis. The shaping method is as follows:

1. The OLC is determined by the geotechnical compaction test. The method is as follows: Select emulsified asphalt content $\mathrm{EC}_{0}$. Change the moisture content for the compaction test. The best moisture content corresponding to the maximum dry density of the mixture under this asphalt content is the OWC. Assuming that the percentages of asphalt and water in the composition of emulsified asphalt are $P_{a}$ and $P_{w}$, respectively, the OLC is:

$$
\mathrm{OLC}=\left(\mathrm{OWC}+E C_{0} \times P_{w}\right) \times 0.7+E C_{0} \times P_{a} \times 0.3
$$

2. Add the mixture aggregate containing RAP to the mixer, with mineral powder and cement (if necessary), and calculate the water to be added according to Eq. 5. For the cold recycled mixture, of which the emulsified asphalt content is $\mathrm{EC}_{1}$, the WC to be added is as follows:

$$
\mathrm{WC}=\left(\mathrm{OLC}-E C_{1} \times P_{a} \times 0.3-E C_{1} \times P_{w} \times 0.7\right) \div 0.7
$$

Add the WC according to the result of Eq. 6 and mix it for 60$70 \mathrm{~s}$.

3. According to the calculated amount of emulsified asphalt, emulsified asphalt is added into the mixer to make the mixture mix evenly, and the mixing time is 60-70 s.

4. Put the well-mixed mixture into the test mold, compact it 50 times on both sides alternately with the Marshall compactor, and put it on the ground at room temperature for $24 \mathrm{~h}$.

5. Put the specimens and the test molds in the oven at $60^{\circ} \mathrm{C}$ for $40-48 \mathrm{~h}$;

6. In spring and autumn, directly take out the specimens and test molds from the oven and immediately compact them 45 times on both sides. In summer, before the end of curing, adjust the temperature of the oven to $70^{\circ} \mathrm{C}$ for more than $2 \mathrm{~h}$, and then take them out and immediately compact them 45 times on both sides.

7. Place the test molds on the ground, cool at room temperature for at least $12 \mathrm{~h}$, and then demould.

\section{Design Indexes and Standards \\ Determination of Splitting Strength Index}

The cold recycled mixture is generally set as the base course or the under layer of pavement. In this position, the cold recycled asphalt pavement may generate tensile stress under vehicle load. Therefore, it is reasonable to use splitting strength as the design index of cold recycled mixture. According to Chinese standards, the dry splitting strength at $15^{\circ} \mathrm{C}$ shall not be less than $0.4 \mathrm{MPa}$ when cold recycled mixture is set as the base course and shall not be less than $0.5 \mathrm{MPa}$ when cold recycled mixture is set as the under layer of pavement.

In this paper, it is proposed that the design standard of cold recycled mixture should be based on the road grade and the structure layer, rather than the unified standard. Combined with the relevant domestic literature, the South African Recycled Mixture Standards (Jenkins and Collings, 2017), and the indoor test results in this paper, it is suggested that the cold recycled mixture can be divided into four grades as shown in Table 7.

\section{Determination of Unconfined Compressive Strength Index}

The compaction rutting of the cold recycled asphalt pavement can be considered the failure of high temperature resistance under the condition of high temperatures. The unconfined compressive strength test can effectively evaluate the high temperature resistance of asphalt mixture. In this paper, the high temperature unconfined compressive strength index will be used to control the ruts produced by secondary compaction.

The temperature of the unconfined compressive strength test can be determined according to the temperature prediction equation in section "Temperature Prediction Equation." Considering the most unfavorable summer construction conditions, the initial temperature of the cold recycled asphalt pavement is taken as $35^{\circ} \mathrm{C}$. Then, according to Equations (1) and (2), the temperature curves at each depth of the cold recycled asphalt pavement can be obtained, as shown in Figure 5. During the construction of HMA on site, the time from the beginning to the end of paving is about $60 \mathrm{~min}$. After $60 \mathrm{~min}$, there is no construction load, and the secondary compaction of cold recycled asphalt pavement will also end. Figure $\mathbf{5}$ indicates that the temperature at a depth of $2 \mathrm{~cm}$ reaches a maximum at $55 \mathrm{~min}$, while the temperatures at depths of 4 and $6 \mathrm{~cm}$ are still rising; at $60 \mathrm{~min}$, the temperature at a depth of $2 \mathrm{~cm}$ drops slightly compared with the highest temperature, and the 
TABLE 6 | Test results of two compactions.

\begin{tabular}{|c|c|c|c|c|c|c|c|}
\hline $\begin{array}{l}\text { First } \\
\text { compaction } \\
\text { temperature } \\
\left({ }^{\circ} \mathrm{C}\right)\end{array}$ & $\begin{array}{c}\text { First compaction } \\
\text { number }\end{array}$ & $\begin{array}{c}\text { Second } \\
\text { compaction } \\
\text { temperature }\left({ }^{\circ} \mathrm{C}\right)\end{array}$ & $\begin{array}{c}\text { Second } \\
\text { compaction } \\
\text { number }\end{array}$ & $\begin{array}{c}\text { Asphalt- } \\
\text { aggregate ratio } \\
(\%)\end{array}$ & $\begin{array}{l}\text { Gross volume } \\
\text { density }\left(\mathrm{g} / \mathrm{cm}^{3}\right)\end{array}$ & $\begin{array}{c}\text { Theoretical } \\
\text { maximum density } \\
\left(\mathrm{g} / \mathrm{cm}^{3}\right)\end{array}$ & Voidage (\%) \\
\hline 25 & 50 & 60 & 20 & 4 & 2.141 & 2.429 & 11.9 \\
\hline 25 & 50 & 60 & 30 & 4 & 2.175 & 2.429 & 10.5 \\
\hline 25 & 50 & 60 & 40 & 4 & 2.188 & 2.429 & 9.9 \\
\hline 25 & 50 & 60 & 50 & 4 & 2.201 & 2.429 & 9.4 \\
\hline 25 & 50 & 60 & 60 & 4 & 2.209 & 2.429 & 9.1 \\
\hline
\end{tabular}

TABLE 7 | Recommended grading standard for cold recycled mixture.

\begin{tabular}{|c|c|c|c|c|}
\hline \multirow[t]{2}{*}{ Cold recycled mixture level } & $\mathbf{I}$ & II & III & IV \\
\hline & $\begin{array}{l}\text { Expressway, middle } \\
\text { and under layer of } \\
\text { first grade highway }\end{array}$ & $\begin{array}{l}\text { Expressway, under } \\
\text { layer and base } \\
\text { course of first grade } \\
\text { highway }\end{array}$ & $\begin{array}{c}\text { Expressway, base } \\
\text { course of first grade } \\
\text { highway }\end{array}$ & $\begin{array}{c}\text { Base course of other } \\
\text { roads }\end{array}$ \\
\hline $15^{\circ} \mathrm{C}$ Splitting strength (Mpa) & $>0.8$ & $0.6-0.8$ & $0.4-0.6$ & $0.2-0.4$ \\
\hline $15^{\circ} \mathrm{C}$ Dry-wet splitting strength ratio (\%) & $>75$ & $>75$ & $>70$ & $>60$ \\
\hline $15^{\circ} \mathrm{C}$ Compressive Resilient Modulus (Mpa) & $1200-1600$ & $1000-1400$ & $800-1200$ & $600-1000$ \\
\hline $20^{\circ} \mathrm{C}$ Compressive Resilient Modulus (Mpa) & $1000-1400$ & $800-1200$ & $600-1000$ & $400-800$ \\
\hline Poisson's ratio & 0.3 & 0.3 & 0.3 & 0.3 \\
\hline
\end{tabular}

temperatures at 4 and $6 \mathrm{~cm}$ rise. Therefore, the most unfavorable time is the period of 55 to $60 \mathrm{~min}$. The temperature of the cold recycled asphalt pavement in this period can be determined by the temperature prediction equations, namely, Equations (1) and (2).The internal temperature of the cold recycled asphalt pavement is considered as average along the depth direction. The average value at $55 \mathrm{~min}$ is $61.0^{\circ} \mathrm{C}$, and the average value at $60 \mathrm{~min}$ is $61.1^{\circ} \mathrm{C}$. Thus, it is suitable to set the temperature of the unconfined compressive strength test as $60^{\circ} \mathrm{C}$.

In the technological transformation project of the NanchangJiujiang Expressway, the compaction ruts occurred after paving HMA if the cold recycled mixture had $4.0 \%$ emulsified asphalt content. However, after reducing emulsified asphalt content to $3.0 \%$, the compaction ruts problem was solved.

In view of the above-mentioned facts, in the laboratory unconfined compressive strength test, four specimens were shaped with emulsified asphalt amounts of $2 \%, 3 \%, 4 \%$, and $5 \%$. The results of the test are shown in Figure 6. As shown in Figure 6, it can be seen that the unconfined compressive strength of emulsified asphalt mixture at $60^{\circ} \mathrm{C}$ first increases and then decreases with the increase of emulsified asphalt content. The unconfined compressive strength of the mixture at $60^{\circ} \mathrm{C}$ with $4 \%$ emulsified asphalt is $0.285 \mathrm{MPa}$, and that with $3.0 \%$ emulsified asphalt is $0.386 \mathrm{MPa}$. If the unconfined compressive strength of cold recycled mixture at $60^{\circ} \mathrm{C}$ is less than $0.285 \mathrm{MPa}$, the index of unconfined compressive strength at $60^{\circ} \mathrm{C}$ should be between 0.285 and $0.386 \mathrm{MPa}$. In this paper, the median value of $0.336 \mathrm{MPa}$ is proposed as the design index.

Based on sections "Specimen Shaping Method" and "Design Indexes and Standards," the improved design method of EACRM is as follows:
1. According to the shaping method determined in section "Specimen Shaping Method," shape four to five groups of specimens with different emulsified asphalt contents. Each group contains six specimens. Obtain the theoretical maximum density of each cold recycled mixture by vacuum method.

2. After demoulding, take out three specimens from each group and measure the physical indexes, such as gross volume density and voidage, by the wax sealing method.

3. Soak the three specimens without wax seals in $25^{\circ} \mathrm{C}$ constant-temperature water for $23 \mathrm{~h}$, and then soak in $15^{\circ} \mathrm{C}$ constant-temperature water for $1 \mathrm{~h}$. Take out the specimens and immediately conduct the wet splitting test at $15^{\circ} \mathrm{C}$. At the same time, conduct the dry splitting test with specimens with wax seals at $15^{\circ} \mathrm{C}$.

4. According to the test results of dry splitting strength and the recommended standards in Table 7 , the range of emulsified asphalt consumption $\mathrm{EC}_{1}-\mathrm{EC}_{2}$ meeting the splitting strength index is determined.

5. Several groups of cylinder specimens $(100 \mathrm{~mm} \times 100 \mathrm{~mm})$ with different emulsified asphalt content are shaped by the gyratory compactor. The shaping method index is $1.25^{\circ}, 600 \mathrm{kPa}$, and 30 times rotated. For each asphalt content, two specimens are shaped for $60^{\circ} \mathrm{C}$ unconfined compressive strength tests. The amount of emulsified asphalt meeting the unconfined compressive strength index ranges from $\mathrm{EC}_{3}$ to $\mathrm{EC}_{4}$.

6. Take the intersection of $\mathrm{EC}_{1}-\mathrm{EC}_{2}$ and $\mathrm{EC}_{3}-\mathrm{EC}_{4}$ as the reasonable asphalt content range of emulsified asphalt cold recycling mixture. If the range of this intersection is 


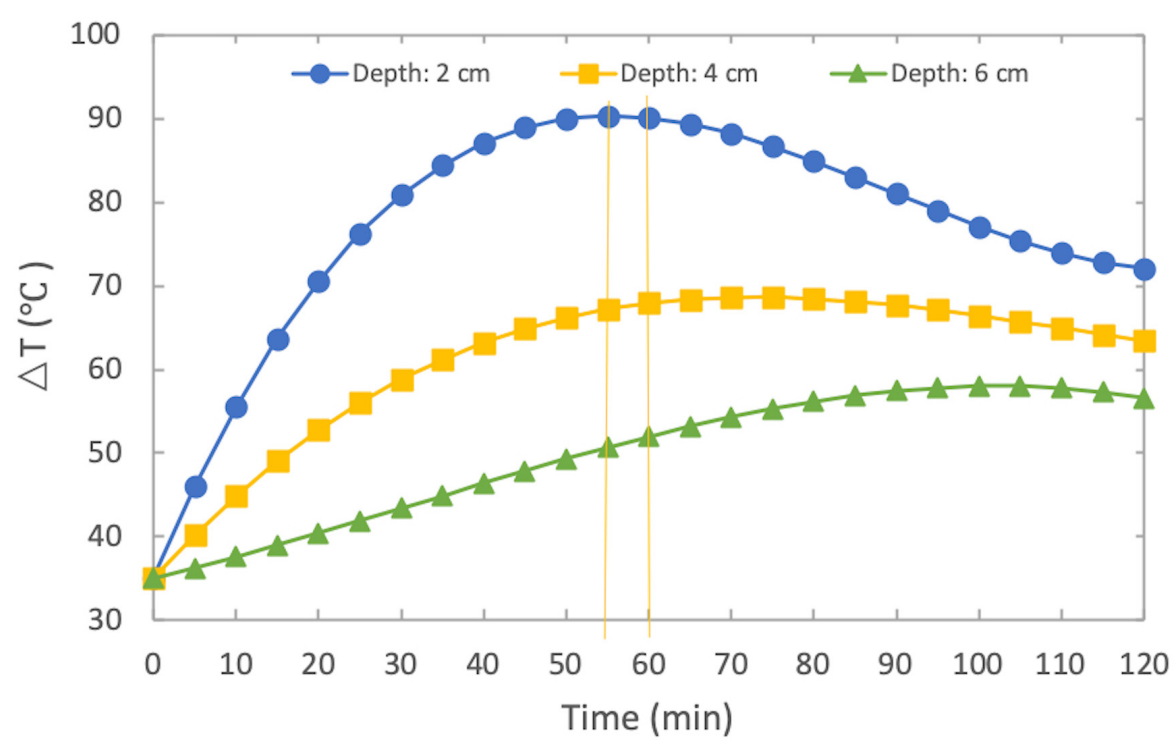

FIGURE 5 | Temperature curves at each depth of cold recycled mixture when HMA paving.

large, the amount of emulsified asphalt shall be selected by comprehensive consideration of the two indexes. If $\mathrm{EC}_{1}-\mathrm{EC}_{2}$ and $\mathrm{EC}_{3}-\mathrm{EC}_{4}$ do not intersect, the cold recycled mixture should be designed again by adjusting the gradation, adding new aggregate, increasing the amount of cement, or changing the quality of emulsified asphalt.

\section{APPLICATION}

\section{Redesign of the Nanchang-Jiujiang Expressway Emulsified Asphalt Cold Recycling Mixture With the Improved Method}

It should be noted that RAP, mineral powder, cement, emulsified asphalt, grading, and other materials used in the improved method were the same as those of the Nanchang-Jiujiang Expressway project. The specific design method is as follows:

1. The OLC of cold recycled mixture was determined according to the maximum dry density of the geotechnical compaction test. When the emulsified asphalt content was $4 \%$, the optimal moisture content was $4.0 \%$. The proportions of asphalt and water in emulsified asphalt were 60 and $38.55 \%$, respectively. Therefore, according to Eq. 3, the optimal liquid content was determined to be $4.6 \%$.

2. Five groups of Marshall specimens were made according to $2,3,4,5$, and $6 \%$ emulsified asphalt content. The optimum WC of each emulsified asphalt was 5.3, 4.6, 4.0, 3.4 , and $2.7 \%$, respectively, according to Eq. 4 . Water, RAP, and cement were added and mixed for $60-70 \mathrm{~s}$.

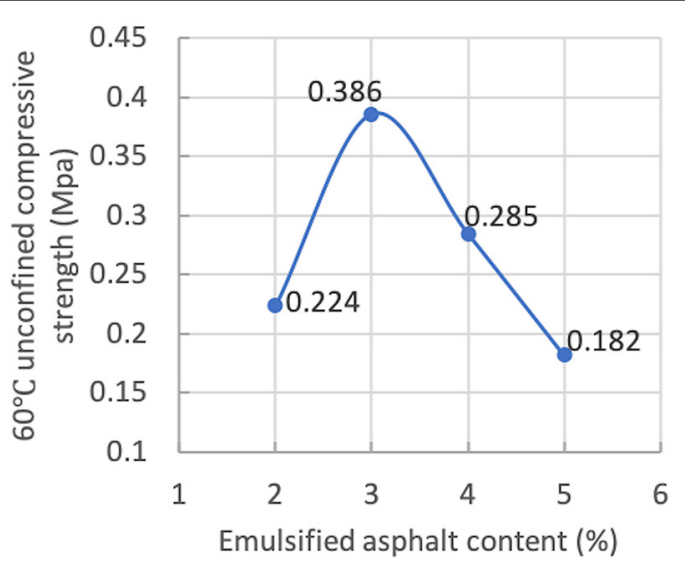

FIGURE $6 \mid 60^{\circ} \mathrm{C}$ unconfined compressive strength (Mpa).

3. According to the calculated amount of emulsified asphalt, emulsified asphalt was added into the mixer, and the mixing time was 60-70 s.

4. The well-mixed mixture was placed in the test molds. The test molds were compacted 50 times on both sides alternately with the Marshall compactor, then put on the ground at room temperature for $24 \mathrm{~h}$.

5. The specimens and the test mold were place in an oven at $60^{\circ} \mathrm{C}$ for $40-48 \mathrm{~h}$.

6. For construction during summer, the oven temperature was set to $70^{\circ} \mathrm{C}$ for more than $2 \mathrm{~h}$ at the end of curing. Specimens were then immediately removed and compacted 45 times on both sides alternately with the Marshall compactor. 


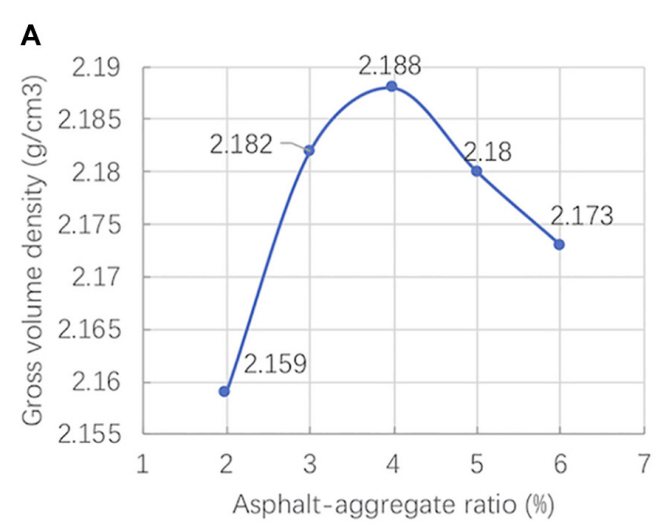

C

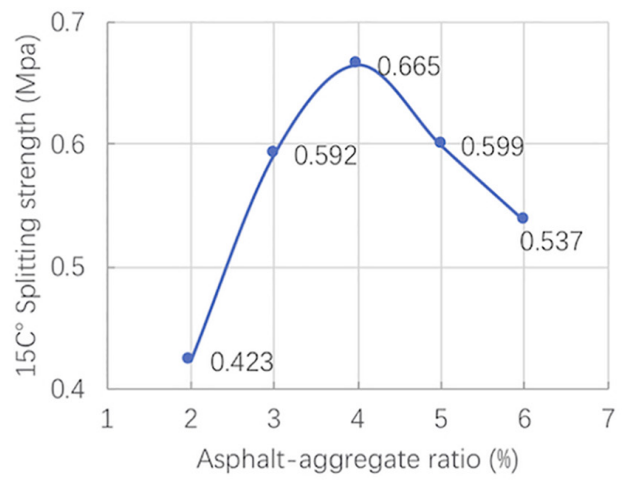

B

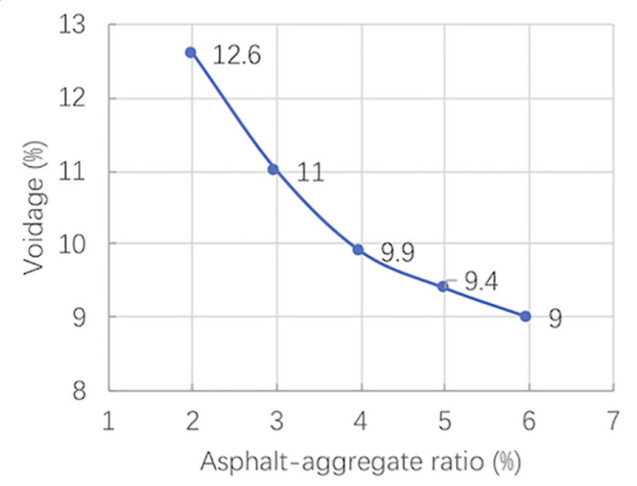

D

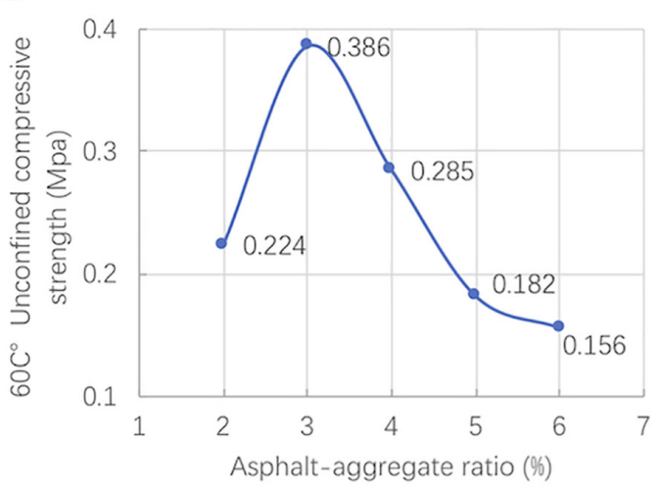

FIGURE 7 | Test results of improved design method. (A) Gross volume density $\left(\mathrm{g} / \mathrm{cm}^{3}\right)$. (B) Voidage (\%). (C) $15^{\circ} \mathrm{C}$ splitting strength (Mpa). (D) $60^{\circ} \mathrm{C}$ unconfined compressive strength (Mpa).

7. The test molds were placed on the ground, cooled at room temperature for at least $12 \mathrm{~h}$, and then demoulded.

8. The gross bulk density, voidage, and dry wet splitting strength of each group of specimens were tested.

9. Several groups of cylinder specimens $(100 \mathrm{~mm} \times 100 \mathrm{~mm})$ with different emulsified asphalt contents $(2,3,4,5$, and $6 \%)$ were shaped by the gyratory compactor. The shaping method indexes were $1.25^{\circ}$, $600 \mathrm{kPa}$, and 30 times rotated. For each asphalt content, two specimens were shaped for $60^{\circ} \mathrm{C}$ unconfined compressive strength tests.

The cold recycled asphalt pavement was designed as a base course for the Nanchang-Jiujiang Expressway. Combined with the test results indicated by Figure 7 and the improved design method, the dry splitting strength should meet the requirements of $0.6-0.8 \mathrm{MPa}$. According to Figure $7 \mathrm{C}$, the range of emulsified asphalt content was about 3.1-5.0\%. At the same time, a $60^{\circ} \mathrm{C}$ unconfined compressive strength index was used, so the emulsified asphalt content range was about 2.6$3.6 \%$ according to Figure 7D. Finally, the reasonable amount of emulsified asphalt was determined to be 3.1-3.6\%. Moreover, for construction during summer, the amount of emulsified asphalt should be selected according to the larger value of

$60^{\circ} \mathrm{C}$ unconfined compressive strength. Therefore, the final amount used was $3.1 \%$.

\section{Comparison of the Design Results Between the Improved Method and the Current Specification in China}

The design method of the emulsified asphalt cold recycling mixture in the current specification in China refers to the Technical Specifications for Highway Asphalt Pavement Recycling (Research Institute of Highway Ministry of Transport $[\mathrm{RIOH}], 2008)$. The design results of the two methods are compared in Table 8.

TABLE 8 | Design results comparison between improved method and current specification.

Index Improved method Current specification

Content of emulsified asphalt (\%)

$15^{\circ} \mathrm{C}$ splitting strength (MPa)

Dry-wet splitting strength ratio (\%)

$60^{\circ} \mathrm{C}$ unconfined

compressive strength (MPa)
3.1

0.6

95

0.39
5

0.659

76

0.182 
It can be seen that the content of emulsified asphalt designed by the current specification is nearly $2 \%$ higher than that of the improved method in this paper. Although the mixture's splitting strength designed by the current specification is slightly higher than that designed by the improved method, its $60^{\circ} \mathrm{C}$ unconfined compressive strength has not reached the standard proposed in the improved method. Thus, when HMA is paved on the EACRM designed by the current specification, secondary compaction occurs, leading to deep ruts. The results of the comparison validate that the proposed design method can effectively avoid early damage to the cold recycled pavement. In fact, after implementing the improved design method, the problem of compaction ruts was solved in a practical project.

\section{CONCLUSION}

In this study, the secondary compaction of EACRM was clarified through field experiments and analysis, which indicates that it is necessary to improve the existing design methods. Therefore, a series of laboratory tests were conducted to determine the specimen shaping method, design indexes, and standards of the improved design method. Finally, the performance of the EACRM designed by the improved design method was compared to that designed by the current specification of China. The results of the comparison validate that the improved design method can effectively avoid early damage to the cold recycled pavement. In summary, the conclusion are as follows:

1. Emulsified asphalt cold recycled mixture is paved at a normal temperature, but it does not mean that the influence of temperature should not be considered. The design methods of common HMA can no longer be applied to the EACRM.

\section{REFERENCES}

Asphalt Recycling and Reclaiming Association [ARRA] (1996). Mixture and Structural Design of Cold Recycled Pavements. Annapolis, MD: ARRA.

Asphalt Recycling and Reclaiming Association [ARRA] (2001). Basic Asphalt Recycling Manual. Annapolis, MD: ARRA.

Deng, X., and Huang, X. (2001). Principle and Method of Pavement Design. Beijing: China Communications Press.

Jenkins, K. J., and Collings, D. C. (2017). Mix design of bitumen-stabilised materials-South Africa and abroad. Road Mater. Pavement Des. 18, 331-349. doi: 10.1080/14680629.2016.1213511

Jiang, Y. J., and Han, Z. Q. (2018). Effect of graded paired emulsified asphalt cold recycled asphalt mixture on road performance. J. Dalian Univ. Technol. 58, 607-614.

Kuna, K., Airey, G. D., Thom, K. (2017). Mix design considerations of foamed bitumen mixtures with reclaimed asphalt pavement material. Int. J. Pavement Eng. 18, 902-915. doi: 10.1080/10298436.2015.1126271

Li, J., Zhang, J., Qian, G., Zheng, J., and Zhang, Y. (2019). Three-Dimensional Simulation of Aggregate and Asphalt Mixture Using Parameterized Shape and Size Gradation. J. Mater. Civ. Eng. 31, 04019004. doi: 10.1061/(asce)mt.19435533.0002623

Li, Z. G., Hao, P. W., and Xu, J. Z. (2016). Study on impacts of freeze-thaw cycles on the shear performances of emulsified asphalt cold recycle mixture. Mater. Rev. $30,121-125$.
2. When HMA is paved, the EACRM will be further compacted, referred to as the secondary compaction process. In the indoor test, the secondary compaction process of EACRM should be simulated by compacting the specimen twice.

3. Based on the measured temperature of the EACRM and the comparison of the void ratio of the drilled core samples of the EACRM before and after HMA paving, the compaction temperature and compaction times were determined. The second compaction temperature is $70^{\circ} \mathrm{C}$ in summer and $60^{\circ} \mathrm{C}$ in spring and autumn; the number of double-sided compactions is 45 .

4. It is suggested that splitting strength $\left(15^{\circ} \mathrm{C}\right)$ and unconfined compressive strength $\left(60^{\circ} \mathrm{C}\right)$ be used as the double index to determine the emulsified asphalt content.

\section{DATA AVAILABILITY STATEMENT}

The datasets generated for this study are available on request to the corresponding author.

\section{AUTHOR CONTRIBUTIONS}

ZC, JY, and YL conducted the experiments. JY and LS were the supervisors of this research work. ZC and TX helped with writing. All authors were involved in the analysis of experimental data and manuscript preparation.

\section{FUNDING}

This research was funded by the National Natural Science Foundation of China, grant number 71471134.

Liu, S. H. (2011). Analysis of Cold Regeneration Mechanism of Semi-rigid Base Asphalt Concrete Pavement. Highway 5, 192-196.

Lu, W. (2001). Design Principle and Method of Asphalt Mixture. Shanghai: Tongji University Press.

Modarres, A., and Ayar, P. (2014). Coal waste application in recycled asphalt mixtures with bitumen emulsion. J. Cleaner Prod. 83, 263-272. doi: 10.1016/ j.jclepro.2014.07.082

Mohammad, L., Abu-Farsakh, M. Y., Wu, Z., Abadie, C. (2003). Louisiana experience with foamed recycled asphalt pavement base materials. Transp. Res. Rec. 1832, 17-24. doi: 10.3141/1832-03

Pouliot, N., Marchand, J., and Pigeon, M. (2003). Hydration mechanisms microstructure and mechanical properties of mortars prepared with mixed binder cement slurry-asphalt emulsion. J. Mater. Civ. Eng. 15, 54-58.

Research Institute of Highway Ministry of Transport [RIOH] (2008). Technical Specifications for Highway Asphalt Pavement Recycling. Beijing: China Communications Press.

Sravani, A., Pramod, K. J., and Nagabhushana, M. N. (2015). Optimization of Recycled Asphalt Pavement in Cold Emulsified Mixtures by Mechanistic Characterization. J. Mat. Civ. Eng. 28, 04015132. doi: 10.1061/(asce)mt.19435533.0001412

Tan, Y. Q., Dong, Z., Cao, L., and Yu-hui, E. (2005). Designing cold recycled asphalt mixtures with superpave volumetric design method. J. Highw. Transp. Res. Dev. $3,31-34$. 
Wang, Z. J., Sha, A. M., Xiao, J. J., and Du, S. W. (2009). Improvement mechanism of cement on microstructure of emulsified asphalt mixture. J. Wuhan Univ. Technol. 31, 16-19.

Wu, C. F., Zeng, M. L., Zhao, M. H., and Zhong, M. W. (2009). Experimental study on road performance of emulsified asphalt cold recycled mixture. Highw. Traffic Technol. 26, $27-32$.

Yang, J., Jiang, T., Sun, L. J., and Liu, L. P. (2010). Study of the emulsified asphalt cold recycled mixture experiment methods considering the secondary compaction process. Highw. Eng. 35, 76-78+133.

Zhang, J. P., Zhu, H. B., and Pei, J. Z. (2015). Evaluation of asphalt emulsification and viscosity of modified asphalt emulsion mortar based on Gompertz model. J. Traffic Transp. Eng. 15, 1-7.
Conflict of Interest: JY was employed by the company Shenzhen High Speed Engineering Consulting Co., Ltd.

The remaining authors declare that the research was conducted in the absence of any commercial or financial relationships that could be construed as a potential conflict of interest.

Copyright (c) 2020 Chen, Liang, Yang, Xu and Sun. This is an open-access article distributed under the terms of the Creative Commons Attribution License (CC BY). The use, distribution or reproduction in other forums is permitted, provided the original author(s) and the copyright owner(s) are credited and that the original publication in this journal is cited, in accordance with accepted academic practice. No use, distribution or reproduction is permitted which does not comply with these terms. 